\title{
Effect of accelerated staining and bleaching on chairside CAD/CAM materials with high and low translucency
}

\author{
Cristina GASPARIK, Bogdan CULIC, Mihai Adrian VARVARA, Alexandru GRECU, Alexandru BURDE \\ and Diana DUDEA \\ Department of Prosthetic Dentistry and Dental Materials, Iuliu Hatieganu University of Medicine and Pharmacy, Cluj-Napoca, Romania
Corresponding author, Bogdan CULIC; E-mail: bculic@umfcluj.ro
}

\begin{abstract}
The aim of the study was to assess the effect of staining and bleaching on CAD/CAM materials with high (HT) and low translucency (LT or T). Samples were stored in coffee and subsequently bleached. CIELAB parameters were recorded at baseline, after coffee immersion, after bleaching. Translucency parameter (TP), whiteness index (WID) and color changes were calculated ( $\left.\Delta \mathrm{E}_{00}\right)$. Influence of staining and bleaching was analyzed with repeated-measures ANOVA and color differences between materials were analyzed with one-way ANOVA $(\alpha=0.05)$. Staining and bleaching significantly affected CIELAB parameters and WID for all materials $(p<0.001)$. TP was significantly influenced by staining and bleaching for Crios and Enamic $(p<0.05)$. Mean color differences were significantly different between materials $(p<0.001)$. The greatest color changes due to staining were observed for Lava Ultimate while the lowest for e.max CAD. Both coffee staining and bleaching induced greater color changes for HT materials of the same brand compared to LT.
\end{abstract}

Keywords: CAD/CAM, Color, Dental ceramics, Composite resin

\section{INTRODUCTION}

CAD/CAM technology has currently become one of the most challenging and dynamic domains in dentistry due to the significant advances in the image acquisition process, restoration designing and manufacturing. Furthermore, there are many highly esthetic materials specifically developed for this technique that are constantly launched to the market, increasing thus the restorative treatment possibilities.

Feldspar ceramic (Vitablocs Mark I and II) was the first material introduced for $\mathrm{CAD} / \mathrm{CAM}$ processing. This material has excellent esthetic properties but is not considered a strong material to withstand high occlusal load; therefore, its clinical indications are limited to anterior veneers and crowns ${ }^{1}$. Although strength is considered one of the most important properties for long term restorations, tougher and stronger materials like lithium disilicate reinforced ceramics or zirconium oxide do not always fulfil the highest esthetic demands. Moreover, these materials often require longer milling times, which consequently lead to faster wearing of the burs and higher maintenance $\operatorname{costs}^{2,3)}$.

Composite resin blocks for $\mathrm{CAD} / \mathrm{CAM}$ technology were introduced to dental practice as alternatives to ceramics ${ }^{4}$. These materials are fabricated under controlled and highly standardized conditions, thus mechanical and optical properties are much improved compared to conventional composite resins ${ }^{5}$. Apart from their better machinability that allow the fabrication of very thin restorations with smooth margins, CAD/CAM resin restorations induce less antagonist wear ${ }^{3,5}$.

According to their microstructure, composite resins for CAD/CAM technology can be divided into two subclasses: with dispersed fillers (DF) and polymer infiltrated ceramic network (PICN) ${ }^{3)}$. DF have a polymeric matrix reinforced with various inorganic fillers ${ }^{6,7}$. A common term used for PICN is hybrid ceramics, because of their unique composition and architecture. Although they contain a ceramic network, according to Mainjot et al. these materials are still composite resins ${ }^{3}$. VITA Enamic, the only available hybrid ceramic, has mechanical properties between ceramic and composite resins $^{8)}$.

Dental composite resins have a tendency to absorb water because of their chemical composition and hydrophilic nature ${ }^{9}$. Consequently, when exposed to various liquids in the oral cavity these materials can suffer a discoloration process. Red wine, coffee, tea, and chlorhexidine are known to have a discoloring effect on resin restorations ${ }^{10)}$. Since color change of resin restorations over time is inevitable, many attempts have been put to improve the altered esthetic appearance of these restorations. Surface polishing and dental bleaching are the most common treatments used for removing the staining from resin restorations ${ }^{11)}$.

Color stainability of composite resins is determined by calculating color differences using $\Delta \mathrm{E}^{*}$ ab or $\Delta \mathrm{E}_{00}$ formulas ${ }^{4)}$ and interpreting results according to visual color difference thresholds ${ }^{12)}$. Bleaching efficiency and stain removal from composite resins is also determined by this method. However, apart from the interpretation of color differences, the assessment of differences in CIE $L^{*}, a^{*}, b^{*}$ or CIE $L^{*}, C^{*}, \mathrm{~h}^{\circ}$ parameters indicate the intimate modification; in addition, a one-dimensional whiteness index is effective in identifying the direction in variation of color. Lately, the use of whiteness indices for quantifying tooth whiteness has become more and more popular ${ }^{13)}$. Additionally, a new customized whiteness index for dentistry (WID) based on CIELAB parameters 
has been proposed. The WID shows a better correlation with visual perception than all other indices ${ }^{14)}$.

Translucency is one of the major factors influencing the appearance of a material and its appropriate selection influences the biomimetic integration of the restoration ${ }^{15)}$. Hence, most of the esthetic dental materials are formulated with different levels of translucency. Translucency is influenced by the composition of the material, mainly by the differences in the refractive index between filler and organic matrix, the amount of filler, and the filler size $\mathrm{e}^{5)}$.

To the best of our knowledge, there is no information available concerning the color stability of CAD/CAM materials with different levels of translucencies, as provided by manufacturers: low level of translucency (LT or T) and high translucency (HT). Therefore, the aim of the present study was to assess the changes in color and translucency of new composite resins, hybrid ceramics, and lithium disilicate with high and low translucency for
CAD-CAM processing after accelerated coffee staining and bleaching with $10 \%$ carbamide-peroxide gel.

The null hypotheses were: 1 ; There was no difference in the effect of accelerated staining and bleaching procedures on CIELAB parameters, TP, WID for direct composites, CAD-CAM composites, hybrid ceramics, lithium disilicate and feldspathic ceramics. 2; There was no difference in the effect of accelerated staining and bleaching procedures on color stability of materials with high and low levels of translucency.

\section{MATERIALS AND METHODS}

Sample preparation, staining and bleaching procedures The materials evaluated in the present study are presented in Table 1. Sample size calculation was carried out using a statistical software (G*Power v3.1.9.2 for MacIntosh [Apple], Heinrich-Heine-Universität, Düsseldorf, Germany) with the following input

Table 1 Type, composition and codification of materials

\begin{tabular}{|c|c|c|c|c|c|c|}
\hline Product & Type & $\begin{array}{l}\text { Block } \\
\text { size }\end{array}$ & Composition* & Shade & $\begin{array}{c}\text { Level of } \\
\text { translucency** }\end{array}$ & Code \\
\hline $\begin{array}{l}\text { Filtek Ultimate } \\
\text { (3M ESPE, St. } \\
\text { Paul, MN, USA) }\end{array}$ & $\begin{array}{l}\text { Composite } \\
\text { resin for direct } \\
\text { restorations }\end{array}$ & N/A & $\begin{array}{l}20 \mathrm{~nm} \text { Silica filler } \\
4-11 \mathrm{~nm} \text { Zirconia filler } \\
80 \mathrm{wt} \% \\
\text { Bis-GMA, UDMA, TEGDMA, } \\
\text { and Bis-EMA resins }\end{array}$ & A3D & N/A & FU \\
\hline $\begin{array}{l}\text { Lava Ultimate } \\
\text { (3M ESPE) }\end{array}$ & $\begin{array}{l}\text { Composite resin } \\
\text { for } \mathrm{CAD} / \mathrm{CAM} \\
\text { restorations }\end{array}$ & $14 \mathrm{~L}$ & $\begin{array}{l}20 \mathrm{~nm} \text { Silica filler } \\
4-11 \mathrm{~nm} \text { Zirconia filler } \\
80 \mathrm{wt} \% \\
\text { Bis-GMA, UDMA, TEGDMA, } \\
\text { and Bis-EMA resins }\end{array}$ & A3 & $\mathrm{HT}$ & $\begin{array}{l}\text { L_HT } \\
\text { L_LT }\end{array}$ \\
\hline $\begin{array}{l}\text { Crios Brilliant } \\
\text { (Coltène/Whaledent, } \\
\text { Altstätten, } \\
\text { Switzerland) }\end{array}$ & $\begin{array}{l}\text { Composite resin } \\
\text { for } \mathrm{CAD} / \mathrm{CAM} \\
\text { restorations }\end{array}$ & 14 & $\begin{array}{l}\text { Barium glass }(<1.0 \mu \mathrm{m}) \\
\mathrm{SiO}_{2}(<20 \mathrm{~nm}) \\
71 \mathrm{wt} \% \\
\text { Cross-linked methacrylates } \\
\text { Pigments }\end{array}$ & A3 & $\mathrm{HT}$ & $\begin{array}{l}\text { CR_HT } \\
\text { CR_LT }\end{array}$ \\
\hline $\begin{array}{l}\text { Shofu Blocks HC } \\
\text { (SHOFU Dental, } \\
\text { Ratingen, Germany) }\end{array}$ & $\begin{array}{l}\text { Composite resin } \\
\text { for CAD/CAM } \\
\text { restorations }\end{array}$ & 14 & $\begin{array}{l}\mathrm{SiO}_{2} \text {, zirconium silicate, } \\
61 \text { wt\% } \\
\text { UDMA, TEGDMA resins }\end{array}$ & $\begin{array}{l}\text { A3 } \\
\text { A3 }\end{array}$ & $\begin{array}{l}\mathrm{HT} \\
\mathrm{LT}\end{array}$ & $\begin{array}{l}\text { S_HT } \\
\text { S_LT }\end{array}$ \\
\hline $\begin{array}{l}\text { VITA Enamic } \\
\text { (VITA Zahnfabrik, } \\
\text { Bad Sackingen, } \\
\text { Germany) }\end{array}$ & $\begin{array}{l}\text { Hybrid ceramic } \\
\text { for } \mathrm{CAD} / \mathrm{CAM} \\
\text { restorations }\end{array}$ & EM-14 & $\begin{array}{l}\mathrm{SiO}_{2}, \mathrm{Al}_{2} \mathrm{O}_{3}, \mathrm{Na}_{2} \mathrm{O} \\
86 \text { wt\% } \\
\text { UDMA, TEGDMA }\end{array}$ & $\begin{array}{l}3 \mathrm{M} 2 \\
3 \mathrm{M} 2\end{array}$ & $\begin{array}{l}\mathrm{HT} \\
\mathrm{T}\end{array}$ & $\begin{array}{l}\text { E_HT } \\
\text { E_T }\end{array}$ \\
\hline $\begin{array}{l}\text { IPS e.max CAD } \\
\text { (Ivoclar Vivadent, } \\
\text { Schaan, } \\
\text { Liechtenstein) }\end{array}$ & $\begin{array}{l}\text { Glass-ceramic } \\
\text { for CAD/CAM } \\
\text { restorations }\end{array}$ & C14 & $\begin{array}{l}\text { Lithium disilicate } \\
\text { reinforced ceramic }\end{array}$ & $\begin{array}{l}\text { A3 } \\
\text { A3 }\end{array}$ & $\begin{array}{l}\mathrm{HT} \\
\mathrm{LT}\end{array}$ & $\begin{array}{l}\text { EX_HT } \\
\text { EX_LT }\end{array}$ \\
\hline $\begin{array}{l}\text { VITABLOCS } \\
\text { Mark II } \\
\text { (VITA Zahnfabrik) }\end{array}$ & $\begin{array}{l}\text { Glass-ceramic } \\
\text { for CAD/CAM } \\
\text { restorations }\end{array}$ & $\mathrm{I} 14$ & Feldspar ceramic & $\mathrm{A} 3 \mathrm{C}$ & N/A & VM_II \\
\hline
\end{tabular}

*Bis-GMA=bisphenol-A-glycidyl methacrylate; UDMA=urethane dimethacrylate; TEGDMA=triethyleneglycol dimethacrylate; Bis-EMA=bisphenol-A-polyethylene glycol diether dimethacrylate.

**HT-High Translucency, LT-Low Translucency, T-Translucent, N/A-Not Applicable 
parameters for repeated measures ANOVA, withinbetween interaction model: effect size $0.40, \alpha$ level $5 \%$, $95 \%$ power, 12 groups, 3 measurements, correlation between measurements 0.50 , and non-sphericity correction 0.75. Based on the calculations, a total sample size of 60 generated a power of 0.98 , therefore the minimum sample size per group was 5 .

The samples were cut to a thickness of $1.1 \mathrm{~mm}$ from CAD-CAM rectangular blocks using a low-speed saw under running water (Isomet 1000, Buehler, Lake Bluff, IL, USA). For IPS e.max CAD LT and HT samples a crystallization cycle was performed with the Programat furnace (Ivoclar Vivadent, Schaan, Liechtenstein) following the indications of the manufacturer. Direct composite resin samples were obtained by packing the resin in a metal sampler (Ceramic Sampler, SmileLine, Saint-Imier, Switzerland). A glass slab was pressed on the top of the resin for preventing the formation of inhibition layer on the surface of resin during curing. Light curing (Halo, Translux Wave, Haereus, Hanau, Germany) was carried out for 20 seconds on both sides of the discs. Samples with a thickness of $1.1 \mathrm{~mm}$ were obtained.

Sandpaper with 500, 800, 1000 grit size was used for manually polishing both sides of the samples down to a thickness of $1 \mathrm{~mm}(+/-0.02 \mathrm{~mm})$. The final thickness of the samples was verified with a digital micrometer (Digital Caliper, Powerfix, Jinjiang Jiaxing Group, Fujian, China). One side of the samples was indented with a fine carbide bur mounted on a low speed hand-piece for marking the side used during the color measurements. An ultrasonic bath filled with distilled water was used for cleaning the samples $\left(2 \min\right.$ at $\left.20^{\circ} \mathrm{C}\right)$.

For the accelerated staining protocol, each sample was stored individually in $3 \mathrm{~mL}$ coffee solution (Nescafé Brasero, Nestlé, Vevey, Switzerland) at room temperature for one week ( $24 \mathrm{~h} /$ day). The coffee solution was refreshed each day. After staining procedures, the samples were stored in distilled water for $24 \mathrm{~h}$, then rinsed and dried. An at-home bleaching protocol using $10 \%$ carbamide peroxide (Professional Teeth Whitening Gel, White Wash Laboratories, Billingham, UK) was applied for $6 \mathrm{~h}$ /day, four consecutive days. Between bleaching sessions, the samples were stored individually in distilled water at room temperature.

\section{Color measurements and calculations}

Color measurement of samples was performed on black, white, and gray backgrounds with a dental spectrophotometer (VITA Easyshade Advance 4.0, VITA Zahnfabrik, Bad Sackingen, Germany). A saturated sucrose solution was interposed between the samples and the backgrounds for ensuring an optical contact. One experienced operator did all measurements. The dental spectrophotometer was allowed to warm-up for 10 min after turning on, and before each measurement the device was calibrated. Each sample was measured three times, at three different time points: at baseline (i), after coffee staining (co), and after bleaching procedures (bl), and CIELAB parameters were recorded.
The CIELAB system allows the representation of colors in a three-dimensional space, using three parameters: $L^{*}$ (lightness) that is represented on a vertical axis and can take values from 0 (black) to 100 (white), and $a^{*}$ and $b^{*}$ chromatic parameters that are represented on two horizontal axes, symbolizing the amount of greennessredness or blueness-yellowness, respectively ${ }^{16)}$.

Translucency parameter (TP) was calculated as follows ${ }^{17}$ :

$$
\mathrm{TP}=\sqrt{\left(L^{*}{ }_{B}-L^{*}{ }_{W}\right)^{2}+\left(a^{*}{ }_{B}-a^{*}{ }_{W}\right)^{2}+\left(b^{*}{ }_{B}-b^{*}{ }_{W}\right)^{2}}
$$

where $L^{*}{ }_{B}, a^{*}{ }_{B}, b^{*}{ }_{B}$ are color parameters recorded on black background and $L^{*}{ }_{W}, a^{*}, b^{*}{ }_{W}$ are CIELAB parameters recorded on white background.

Whiteness index $\left(\mathrm{WI}_{\mathrm{D}}\right)$ was also calculated based on CIELAB parameters ${ }^{14)}$ :

$$
\mathrm{WI}_{\mathrm{D}}=0.511 L^{*}-2.324 a^{*}-1.100 b^{*}
$$

where $L^{*}, a^{*}, b^{*}$ are color parameters of samples recorded on grey background.

Color changes of the samples after coffee staining $\left(\Delta \mathrm{E}_{00} c 0-\mathrm{i}\right)$, bleaching ( $\Delta \mathrm{E}_{00}$ bl-co) and between initial and final situation $\left(\Delta \mathrm{E}_{00} \mathrm{bl}-\mathrm{i}\right)$ were calculated for grey background using the color difference formula CIEDE2000 $\left(\Delta \mathrm{E}_{00}\right)$. The supplementary data file recommended by Sharma et al. was used for calculations ${ }^{18-20)}$.

Descriptive statistics, testing for normal distribution and data analyses were performed with statistical software (SPSS Statistics v.23 for MacIntosh [Apple], IBM, Chicago, IL, USA). The influence of staining and bleaching treatments on CIELAB parameters, TP, $\mathrm{WI}_{\mathrm{D}}$ of materials was tested using the repeated measures ANOVA test $(\alpha=0.05)$ and pairwise comparisons between groups were adjusted by least significant difference (LSD) method. The color differences between materials induced by staining or bleaching were analyzed with one-way analysis of variance (ANOVA) test $(\alpha=0.05)$. Multiple comparisons between mean color differences of materials were analyzed with Tukey Honest Significant Difference (HSD) test $(\alpha=0.05)$.

\section{RESULTS}

The results of the repeated measures ANOVA showed that accelerated staining and bleaching treatments had a significant effect on the $L^{*}$ parameter for all tested materials $(\mathrm{F}=983.770, p<0.001)$ and the interaction between treatment type and material was significant $(\mathrm{F}=121.941, p<0.001)$. Crios Brilliant HT and Lava Ultimate HT showed the greatest decrease in lightness after staining, while VITA Enamic T the lowest. After bleaching procedure, the lightness of the samples did not return to the initial level, for none of the tested materials. However, the greatest bleaching effect was observed for Shofu Blocks HT and LT, Filtek Ultimate and Lava Ultimate LT.

Accelerated staining and bleaching treatments had a significant effect on both $a^{*}$ and $b^{*}$ chromatic 
parameters for all tested materials ( $\mathrm{F}=1149.910$, $p<0.001$ and $\mathrm{F}=1679.145, p<0.001$ respectively) and the interaction between treatment type and material was also significant $(\mathrm{F}=41.754, p<0.001$ and $\mathrm{F}=104.019$, $p<0.001$ respectively). Accelerated staining induced the greatest increase in $a^{*}$ parameter for Lava Ultimate LT and HT, Crios Brilliant LT and HT. Bleaching did not restore the initial level for $a^{*}$, yet for Crios Brilliant LT, Lava Ultimate LT and HT the greatest bleaching effect was observed. After coffee staining, Filtek Ultimate and Lava Ultimate LT had the greatest increase in $b^{*}$ parameter.

The tested materials showed different values of
WID at baseline (Table 2). Accelerated staining and bleaching treatments significantly influenced the values of the whiteness index for all tested materials $(\mathrm{F}=1963.820, p<0.001)$, with the interaction effect also significant $(\mathrm{F}=88.360, p<0.001)$. However, the multiple comparisons showed no significant change in WID after accelerated staining and bleaching for e.max CAD LT and HT ( $p>0.05)$. Lava Ultimate HT showed the greatest decrease in whiteness after coffee staining, followed by Filtek Ultimate and Lava Ultimate LT. Moreover, after coffee staining and bleaching HT samples showed greater variation in WID than $\mathrm{LT}$, for all CAD/CAM composite materials.

Table 2 Mean differences and standard deviations of whiteness indexes after coffee staining $\left(\Delta \mathrm{WID}_{\text {co } \_ \text {i }}\right)$, bleaching $\left(\Delta \mathrm{WID} \mathrm{Dl}_{\mathrm{bl} \_\mathrm{o}}\right)$, and the residual difference compared to baseline $\left(\Delta \mathrm{WID}_{\mathrm{bl} \_\mathrm{i}}\right)$

\begin{tabular}{|c|c|c|c|c|}
\hline & $\mathrm{WID}_{\mathrm{i}}$ & $\Delta \mathrm{WID}_{\text {co_i }}$ & $\Delta \mathrm{WID}_{\text {bl_co }}$ & $\Delta \mathrm{WID}_{\mathrm{bl} \_\mathrm{i}}$ \\
\hline Filtek Ultimate & $25.33(0.52)$ & $-6.67(1.24)$ & $3.92(1.05)$ & $-2.75(0.34)$ \\
\hline Lava HT & $28.98(0.43)$ & $-8.06(2.25)$ & $5.45(1.24)$ & $-2.62(1.21)$ \\
\hline Lava LT & $18.65(0.43)$ & $-6.61(1.00)$ & $3.95(1.38)$ & $-2.66(0.46)$ \\
\hline Crios HT & $24.72(0.24)$ & $-6.36(1.41)$ & $4.23(1.60)$ & $-2.13(0.56)$ \\
\hline Crios LT & $0.84(0.47)$ & $-5.41(1.18)$ & $4.57(1.03)$ & $-0.83(0.60)$ \\
\hline Shofu HT & $27.27(0.21)$ & $-4.64(0.49)$ & $2.12(0.32)$ & $-2.51(0.48)$ \\
\hline Shofu LT & $15.79(0.20)$ & $-4.12(0.49)$ & $1.46(0.67)$ & $-2.66(0.55)$ \\
\hline Enamic HT & $9.21(0.50)$ & $-1.51(0.25)$ & $1.36(0.51)$ & $-0.15(0.31)$ \\
\hline Enamic T & $-9.36(0.41)$ & $-1.73(0.67)$ & $2.17(0.77)$ & $0.44(0.28)$ \\
\hline e.max CAD HT & $35.28(0.22)$ & $0.36(0.17)$ & $0.42(0.36)$ & $0.78(0.31)$ \\
\hline e.max CAD LT & $23.30(0.62)$ & $-0.29(0.55)$ & $0.70(0.52)$ & $0.40(0.20)$ \\
\hline VITA Mark II & $25.46(0.37)$ & $-1.86(0.48)$ & $0.97(0.55)$ & $-0.89(0.28)$ \\
\hline
\end{tabular}

Table 3 Mean differences and standard deviations of TP after coffee staining $\left(\Delta \mathrm{TP}_{\text {со } \_ \text {i }}\right)$, bleaching $\left(\Delta \mathrm{TP}_{\mathrm{bl} \_\mathrm{co}}\right)$, and the residual difference compared to baseline $\left(\Delta \mathrm{TP}_{\mathrm{bl} \_\mathrm{i}}\right)$

\begin{tabular}{lcccr}
\hline & \multicolumn{1}{c}{$\mathrm{TP}_{\mathrm{i}}$} & $\Delta \mathrm{TP}_{\text {co_i }}$ & $\Delta \mathrm{TP}_{\text {bl_co }}$ & $\Delta \mathrm{TP}_{\text {bl_i }}$ \\
\hline Filtek Ultimate & $21.65(0.62)$ & $-0.31(0.53)$ & $0.20(0.43)$ & $-0.11(0.32)$ \\
Lava HT & $21.93(0.38)$ & $-0.63(0.35)$ & $0.46(1.15)$ & $-0.17(1.11)$ \\
Lava LT & $21.16(0.14)$ & $-0.21(0.49)$ & $0.03(0.35)$ & $-0.17(0.23)$ \\
Crios HT & $21.81(0.16)$ & $-0.97(0.32)$ & $-0.24(0.63)$ & $-1.21(0.38)$ \\
Crios LT & $19.88(0.52)$ & $-0.44(0.48)$ & $-0.33(1.02)$ & $-0.77(1.13)$ \\
Shofu HT & $23.02(0.22)$ & $-0.36(0.31)$ & $0.40(0.24)$ & $0.04(0.21)$ \\
Shofu LT & $21.74(0.45)$ & $-0.14(0.17)$ & $0.27(0.13)$ & $0.12(0.12)$ \\
Enamic HT & $18.84(0.54)$ & $-0.07(0.36)$ & $-0.47(0.33)$ & $-0.54(0.27)$ \\
Enamic T & $16.37(0.25)$ & $-0.10(0.25)$ & $-0.25(0.22)$ & $-0.35(0.31)$ \\
e.max CAD HT & $18.87(0.32)$ & $0.24(0.24)$ & $-0.18(0.23)$ & $0.05(0.10)$ \\
e.max CAD LT & $17.79(0.24)$ & $0.13(0.24)$ & $-0.13(0.32)$ & $0.01(0.14)$ \\
VITA Mark II & $19.88(0.27)$ & $-0.35(0.21)$ & $0.23(0.15)$ & $-0.12(0.17)$ \\
\hline
\end{tabular}


Table 4 Summary of one-way ANOVA for testing the differences in $\Delta \mathrm{E}_{00}$ between groups of materials after coffee staining, bleaching, and the residual color difference

\begin{tabular}{|c|c|c|c|c|c|}
\hline Source & Sum of squares & $\mathrm{df}$ & Mean square & $\mathrm{F}$ & $p$ \\
\hline$\Delta \mathrm{E}_{00 \text { co_i }}$ & 151.555 & 11 & 13.778 & 130.814 & $<0.001$ \\
\hline$\Delta \mathrm{E}_{00 \text { bl_co }}$ & 85.193 & 11 & 7.745 & 119.010 & $<0.001$ \\
\hline$\Delta \mathrm{E}_{00 \mathrm{bl} \_\mathrm{i}}$ & 26.576 & 11 & 2.416 & 45.553 & $<0.001$ \\
\hline
\end{tabular}

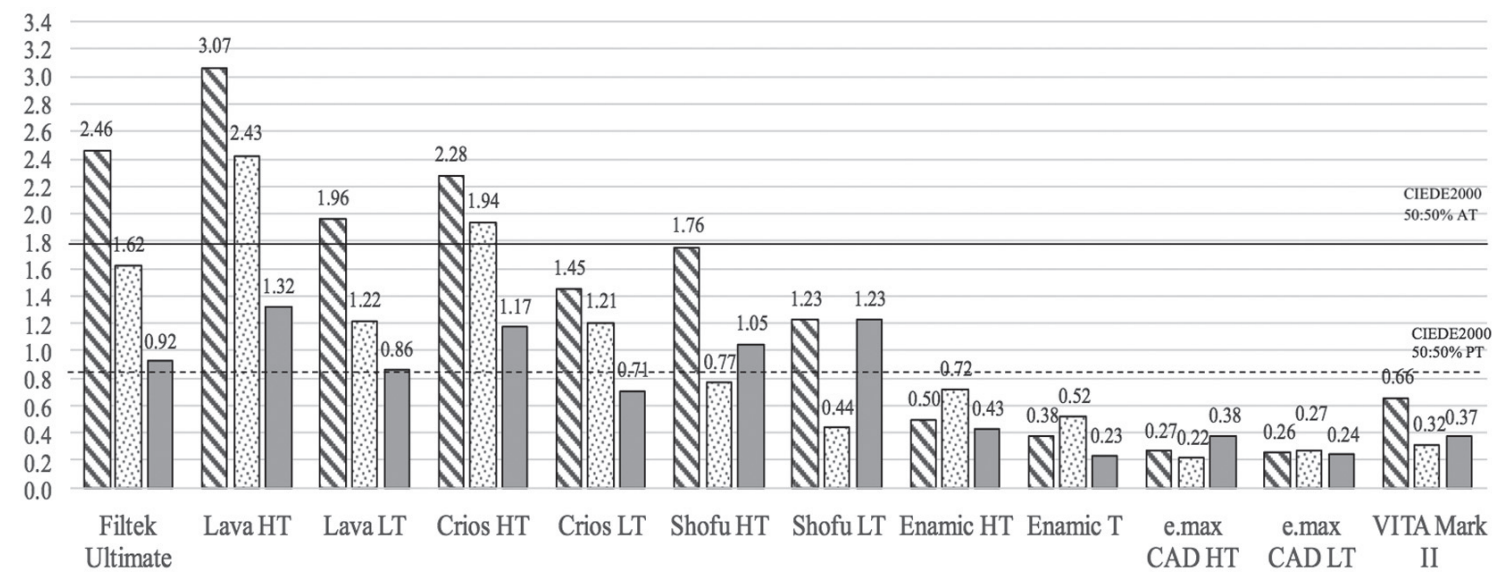

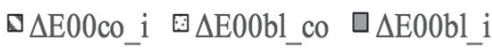

Fig. 1 Mean color differences after coffee staining $\left(\Delta \mathrm{E}_{00 \text { co } \_ \text {i }}\right)$, bleaching $\left(\Delta \mathrm{E}_{00 \text { bl_co }}\right)$, and the residual color difference $\left(\Delta \mathrm{E}_{00} \mathrm{bl} \_\right.$) of 1-mm A3 sample groups (CIEDE2000 50:50\% Perceptibility threshold $=0.8$, CIEDE2000 50:50\% Acceptability threshold =1.8).

The results of the repeated measures ANOVA revealed that TP was also significantly influenced by staining and bleaching $(\mathrm{F}=38.757, p<0.001)$. The interaction effect between material and treatment was significant $(\mathrm{F}=7.973, \quad p<0.001)$. The multiple comparisons showed significant changes in TP only for Crios Brilliant LT and HT, and VITA Enamic T and HT $(p<0.05$, Table 3$)$.

The one-way ANOVA revealed that mean color differences $\left(\Delta \mathrm{E}_{00}\right.$ co-i, $\Delta \mathrm{E}_{00}$ bl-co, $\left.\Delta \mathrm{E}_{00} \mathrm{bl}-\mathrm{i}\right)$ were significantly different between materials $(p<0.001$, Table 4). The color differences induced by staining and bleaching are presented in Fig. 1. The greatest color changes due to coffee staining were observed for Lava Ultimate LT and HT, Filtek Ultimate, and Crios Brilliant HT (above the acceptability threshold of 1.8).

IPS e.max CAD LT and HT, VITA Enamic T and HT showed the smallest color variations (below the perceptibility threshold of 0.8). Multiple comparison tests showed no significant differences between the mean color differences calculated for these materials $(p>0.05)$. The color differences after coffee staining calculated for Crios Brilliant LT, Shofu Blocks LT and HT were situated between 50:50\% PT and 50:50\% AT.

The greatest color changes induced by bleaching were observed for Lava Ultimate $\mathrm{HT}$ and Crios Brilliant HT (above 50:50\% AT), while the smallest were detected for Shofu Blocks LT and HT, VITA Enamic T and HT,
IPS e.max CAD LT and HT, and Vitablocs Mark II (below 50:50\% PT).

Both coffee staining and bleaching procedures induced higher color changes for HT materials compared to LT, for the same brand. However, for VITA Enamic T and HT, IPS e.max CAD LT and HT the differences were not statistically significant $(p>0.05)$.

The residual color difference $\left(\Delta \mathrm{E}_{00} \mathrm{bl}-\mathrm{i}\right)$ was below the 50:50\% PT only for Crios Brilliant LT, VITA Enamic $\mathrm{T}$ and HT, IPS e.max CAD LT and HT, and Vitablocs Mark II.

\section{DISCUSSION}

The major cause of color differences resulted after staining and bleaching between materials tested is the difference in their chemical composition and structural organization. Among all, ceramics based on lithium disilicate or feldspar which are highly dense materials showed the best color stability. These results are in accordance with previous studies ${ }^{1,4,5,10)}$. It was shown that the organic matrix is mainly responsible for discoloration. Hybrid ceramics, materials that have a low content of organic component showed also color differences below perceptibility threshold. Composite-based materials have in their composition an increased percentage of organic matrix which is linked to a lower color stability. HT composite resin blocks have less inorganic particles 
compared to LT materials and therefore this could explain their inferior resistance to staining.

The first null hypothesis was rejected since direct composites and $\mathrm{CAD} / \mathrm{CAM}$ composites underwent greater color changes than ceramic-based materials after accelerated coffee staining and bleaching. Filtek Ultimate, Lava Ultimate LT and HT showed the greatest stain susceptibility, which may have occurred because of their chemical composition. Bis-GMA monomers, that are found in the composition of Filtek Ultimate and Lava Ultimate are more hydrophilic compared to UDMA or TEGDMA $^{5,21,22)}$. Moreover, the final color is perceivable differently in comparison with the initial situation (after staining and bleaching), which means that the effect of the whitening gel did not neutralize entirely the pigmentation. Lithium-disilicate, feldspar ceramic and hybrid ceramic proved the best color stability.

Discoloration of dental materials can be caused by different factors. Among the extrinsic factors producing discoloration of dental restorations are dental plaque accumulation and surface staining ${ }^{5}$. Surface polishing and professional cleaning or bleaching can remove superficial staining. However, if the discoloration involves deeper layers, these treatment methods are no longer efficient and restoration replacement should be considered. The color change is influenced by the type of resin, degree of polymerization, photoinitiator system, surface finishing, colorant type, contact time between staining agents and resins, oral hygiene habits,23-26). Previous studies reported that the type of resin significantly influences the amount of discoloration ${ }^{5,21,22,27)}$. Because of its lower hydrophilic properties, UDMA appears to be more color stable than Bis-GMA. TEGDMA also seems to be more color-resistant than Bis-GMA. Therefore, most of the composite resins recently introduced to the market are mainly formulated based on TEGDMA and UDMA.

The second null hypothesis was also rejected because significant differences in color stability were found between LT and HT materials of the same brand and color. HT materials showed greater color differences than LT, although the color differences were not perceivable for ceramic-based materials. An explanation could be the different ratio between organic matrix and inorganic filler among different translucencies of composite-based materials. The difference in color stability between HT and LT CAD/CAM composite resins has an important clinical significance particularly in the case of several restorations placed one next to the other, as is the case of veneers and full coverage crowns in the upper frontal area.

The discoloration effect induced by staining agents on teeth or various dental materials can be appreciated by calculating color differences between CIELAB parameters of the samples before and after treatment. In this respect, the most widely used color difference formula is $\Delta \mathrm{E}^{*}$ ab. The more recently introduced color difference formula, CIEDE2000, has been proved to be better correlated to visual perception and thus should be used in color calculations ${ }^{18}$. Regardless of which formula is used, the interpretation of the color difference values has to be related to the perceptibility (PT) and acceptability thresholds (AT) for having the true clinical significance of the data. In a recent multicentric study it was found that the $50: 50 \% \mathrm{PT}$ and $50: 50 \% \mathrm{AT}$ in Dentistry are 0.8 and 1.8 respectively for $\Delta \mathrm{E}_{00}$, and 1.2 and 2.7 respectively for $\Delta \mathrm{E}^{*} \mathrm{ab}^{28)}$.

In the present study, the color changes induced by staining and bleaching were below the perceptibility threshold only for hybrid ceramics, lithium disilicate and feldspar ceramics. Accelerated coffee staining induced a significant decrease in lightness and a color shifting towards reddish-yellowish for composite based materials. Additionally, coffee staining and bleaching induced greater variation of the WID for HT samples than for LT. Although the variation of the WID showed more significant changes for $\mathrm{CAD} / \mathrm{CAM}$ composite resins and direct composites, as the color difference formula also proved, the clinical interpretation of the WID values is not possible since visual thresholds are not yet available.

One-week immersion of samples in coffee solution was used in the present study. This protocol was followed since previous research demonstrated that within this time interval composites take up significant staining. This immersion time is equivalent to seven months of coffee drinking ${ }^{10,29,30)}$. For the bleaching procedures, an at-home bleaching protocol with $10 \%$ carbamide-peroxide was used as it is one of the most accepted bleaching treatment by patients, with the least side effects ${ }^{311}$.

Bleaching effect of different agents on restorative materials was tested in several previous studies ${ }^{10,11,32)}$. One study found no significant differences in bleaching efficiency of $10 \%$ carbamide-peroxide over composite resins ${ }^{32}$. In our study, except lithium-disilicate, the bleaching procedure with $10 \%$ carbamide-peroxide could not effectively remove the staining from the surface of the samples. Similar results are presented by Alharbi et al. in a recent study ${ }^{11)}$. They concluded that bleaching with $40 \%$ hydrogen-peroxide was able to remove the stains to a clinically acceptable level only for hybrid ceramics and feldspar ceramics.

Translucency parameter was first introduced as a direct measure of translucency for maxillofacial elastomers, and it was calculated as the color difference between CIELAB parameters of the sample with specified thickness placed in optical contact over black and white backings ${ }^{17}$. Translucency and opacity are material properties that vary in time and can be modified by water absorption, chemical degradation, and microfractures of the composite resins ${ }^{33}$. In the present study, the initial translucency of the tested materials at $1 \mathrm{~mm}$ thickness was different, VITA Enamic T being the least translucent whereas Shofu Blocks HT the most translucent. Staining and bleaching procedures significantly affected TP only in the case of Crios Brilliant HT and LT, and VITA Enamic HT and T. The decrease in translucency after coffee immersion could have occurred because of the stains absorbed on the surface of the samples. 
A limitation of the present study is that the samples did not follow any clinical polishing or glazing procedures. However, a standardized fabrication protocol was used for all the samples. Another limitation is that only 1 mm A3 shaded samples were investigated. Further studies should be conducted for other clinically relevant thicknesses and shades.

\section{CONCLUSIONS}

Within the limitation of the present study, it can be concluded that color changes induced by accelerated staining and bleaching procedures were clinically significant for direct and CAD/CAM composite materials. Additionally, the discoloration was more important for HT materials than for LT. The ceramic based materials did not exhibit perceivable color changes after staining and bleaching.

\section{ACKNOWLEDGMENTS}

This study was supported by research project "Development of an innovative glass-fiber reinforced composite resin material for $\mathrm{CAD} / \mathrm{CAM}$ applications in Dentistry (IFRCD)". PN-III-P2-2.1-PED-2016-1936. Contract nr. 253/2017.

The authors thank Ms. Justine DECROIX for the help with sample fabrication.

\section{REFERENCES}

1) Li RW, Chow TW, Matinlinna JP. Ceramic dental biomaterials and CAD/CAM technology: state of the art. J Prosthodont Res 2014; 58: 208-216.

2) Chavali R, Nejat AH, Lawson NC. Machinability of CADCAM materials. J Prosthet Dent 2017; 118: 194-199.

3) Mainjot AK, Dupont NM, Oudkerk JC, Dewael TY, Sadoun MJ. From artisanal to CAD-CAM blocks: State of the art of indirect composites. J Dent Res 2016; 95: 487-495.

4) Acar O, Yilmaz B, Altintas SH, Chandrasekaran I, Johnston WM. Color stainability of CAD/CAM and nanocomposite resin materials. J Prosthet Dent 2016; 115: 71-75.

5) Stawarczyk B, Sener B, Trottmann A, Roos M, Ozcan M, Hämmerle CH. Discoloration of manually fabricated resins and industrially fabricated $\mathrm{CAD} / \mathrm{CAM}$ blocks versus glassceramic: effect of storage media, duration, and subsequent polishing. Dent Mater J 2012; 31: 377-383.

6) Ruse ND, Sadoun MJ. Resin-composite blocks for dental CAD/CAM applications. J Dent Res 2014; 93: 1232-1234.

7) Ferracane JL. Resin composite — state of the art. Dent Mater 2011; 27: 29-38.

8) Della Bona A, Corazza PH, Zhang Y. Characterization of a polymer-infiltrated ceramic-network material. Dent Mater 2014; 30: 564-569.

9) Nguyen JF, Migonney V, Ruse ND, Sadoun M. Resin composite blocks via high-pressure high-temperature polymerization. Dent Mater 2012; 28: 529-534.

10) Quek SHQ, Yap AUJ, Rosa V, Tan KBC, Teoh KH. Effect of staining beverages on color and translucency of CAD/CAM composites. J Esthet Restor Dent 2018; 30: E9-E17.

11) Alharbi A, Ardu S, Bortolotto T, Krejci I. In-office bleaching efficacy on stain removal from CAD/CAM and direct resin composite materials. J Esthet Restor Dent 2018; 30: 51-58.

12) ISO. ISO/TR 28642. Dentistry -Guidance on colour measurement. 2016

13) Joiner A, Luo W. Tooth colour and whiteness: A review. J Dent 2017; 67S: S3-S10.

14) Perez MM, Ghinea R, Rivas MJ, Yebra A, Ionescu AM, Paravina RD, et al. Development of a customized whiteness index fordentistry based on CIELAB color space. Dent Mater 2016; 32: 461-467.

15) Kelly JR, Benetti P. Ceramic materials in dentistry: historical evolution and current practice. Aust Dent J 2011; 56: 84-96.

16) Berns RS. Billmeyer and Saltzman's Principles of Color Technology. 3rd ed. New York: John Wiley \& Sons; 2000.

17) Johnston WM, Ma T, Kienle BH. Translucency parameter of colorants for maxillofacial prostheses. Int J Prosthodont 1995; 8: 79-86.

18) Luo MR, Cui G, Rigg B. The development of the CIE 2000 colour-difference formula: CIEDE2000. Color Res Appl 2001; 26: 340-350.

19) Ghinea R, Perez MM, Herrera LJ, Rivas MJ, Yebra A, Paravina RD. Color difference thresholds in dental ceramics. J Dent 2010; 38: e57-e64.

20) Sharma G, Wu W, Dalal EN. The CIEDE2000 color-difference formula: implementation notes, suplementary test data, and mathematical observations. Color Res Appl 2005; 30: 21-30.

21) Bagheri R, Burrow MF, Tyas M. Influence of food-simulating solutions and surface finish on susceptibility to staining of aesthetic restorative materials. J Dent 2005; 33: 389-398.

22) KalachandraS, TurnerDT. Water sorption of polymethacrylate networks; bisGMA/ TEGDMA copolymers. J Biomed Mater Res 1987; 21: 329-338.

23) Çelık EU, Aladağ A, Türkün LŞ, Yilmaz G. Color changes of dental resin composites before and after polymerization and storage in water. J Esthet Restor Dent 2011; 23: 179-188.

24) Imazato S, Tarumi H, Koboyashi K, Hiraguri H, Oda K, Tsuchitani Y. Relationship between degree of conversion and internal discoloration of light activated composites. Dent Mater 1995; 14: 23-30.

25) Malhotra N, Shenoy RP, Acharya S, Shenoy R, Mayya S. Effect of three indigenous food stains on resin-based, microhybrid-, and nanocomposite. J Esthet Restor Dent 2011; 23: 250-257.

26) Usumez A, Ozturk N, Ozturk B. Two-year color changes of light-cured composites: influence of different light-curing units. Oper Dent 2005; 30: 655-660.

27) Janda R, Roulet JF, Kaminsky M, Steffin G, Latta MC. Color stability of resin matrix restorative materials as a function of the method of light activation. Eur J Oral Sci 2004; 112: 280285.

28) Paravina RD, Ghinea R, Herrera LJ, Della Bona A, Igiel C, Linninger $\mathrm{M}$, et al. Color difference thresholds in dentistry. J Esthet Restor Dent 2015; 27: S1-S9.

29) Shiozawa M, Takahashi H, Asakawa Y, Iwasaki N. Color stability of adhesive resin cements after immersion in coffee. Clin Oral Investig 2015; 19: 309-317.

30) Arocha MA, Basilio J, Llopis J, Di Bella E, Roig M, Ardu $\mathrm{S}$, et al. Colour stainability of indirect CAD-CAM processed composites vs. conventionally laboratory processed composites after immersion in staining solutions. J Dent 2014; 42: 831838.

31) Auschill TM, Hellwig E, Schmidale S, Sculean A, Arweiler NB. Efficacy, side-effects and patients' acceptance of different bleaching techniques (OTC, in-office, at-home). Oper Dent 2005; 30: 156-163.

32) Monaghan P, Lim E, Lautenschlager E. Effect of home bleaching preparations on composite resin color. J Prosthet Dent 1992; 68: 575-578.

33) Lee BS, Huang SH, Chiang YC, Chien YS, Mou CY, Lin CP. Development of in vitro tooth staining model and usage of catalysts to elevate the effectiveness of tooth bleaching. Dent Mater 2008; 24: 57-66. 